\title{
Thoracoscopic Pneumonectomy for Non-Small Cell Lung Cancer (NSCLC): A Case Report and Review of the Literature
}

\author{
Oya Andacoglu ${ }^{1 *}$, James D. Maloney ${ }^{1,2}$ \\ ${ }^{1}$ Department of Surgery, University of Wisconsin, Madison, USA; ${ }^{2}$ Section of Thoracic Surgery, William S. Middleton Memorial \\ VA Hospital, Madison, USA. \\ Email: *oandacoglu@uwhealth.org
}

Received April 14 ${ }^{\text {th }}, 2013$; revised May $18^{\text {th }}, 2013$; accepted May 28 ${ }^{\text {th }}, 2013$

Copyright (C 2013 Oya Andacoglu, James D. Maloney. This is an open access article distributed under the Creative Commons Attribution License, which permits unrestricted use, distribution, and reproduction in any medium, provided the original work is properly cited.

\begin{abstract}
Minimally invasive resection of lung cancer remains surprisingly uncommon in comparison to the adoption of similar techniques in other surgical disciplines. The reported use of video-assisted thoracic surgery (VATS) lobectomy for anatomic resections in comparison to open lobectomy ranges from $10 \%-40 \%$ even though it has been demonstrated to be equivalent in safety and accomplishes the same oncologic goals. Further, it may provide improved survival outcomes as others have reported benefits in perioperative recovery and patient satisfaction. VATS pneumonectomy has been far less commonly described despite the physiologic advantages such as less blood loss, shorter intensive care stay, and less respiratory compromise. This report specifically addresses this lacuna by drawing upon the successful case of a VATS pneumonectomy with fissure invasion and then considering why minimally invasive VATS techniques remain underutilized. In conclusion, we suggest that focused thoracic surgery fellowship training in VATS techniques will make thoracoscopic surgery a more conventional technique rather than a challenging procedure.
\end{abstract}

Keywords: Pneumonectomy; Video-Assisted Thoracoscopy; Lung Cancer

\section{Case}

A 48-year old female patient presented with a hemoptysis episode that subsided on its own. Initial chest $\mathrm{x}$-ray demonstrated a left upper lobe nodule. CT scan confirmed a $3-\mathrm{cm}$ lingular mass abutting the mediastinum along the left ventricle free wall with some nodular component that appears to extend toward the lower lobe (Figures 1-3). Positron Emission Tomography (PET) scan demonstrated intense hypermetabolism within the mass with an SUV of 10.2 consistent with malignancy. No hypermetabolic mediastinal or distant metastatic disease was seen. Adenocarcinoma was shown on bronchoscopic biopsy. Pulmonary function was excellent with an FEV1 $>100 \%$ predicted. Clinical staging suggested that surgical resection with upper lobectomy and possible contiguous resection of the anterior medial basal segment of the lower lobe was needed. The patient was informed about the possibility of wider resections including pneu-

${ }^{*}$ Corresponding author. monectomy. A standard video-assisted thoracic surgery (VATS) approach was employed using a $5 \mathrm{~cm} 4^{\text {th }}$ intercostal space access incision, a $7^{\text {th }}$ intercostal space camera port and a posterior retraction port. Upon inspecting the lung, we found the tumor within the lingula crossing the fissure to be incomplete. The tumor was too approximate to the inferior pulmonary vein to allow extended lobectomy with a portion of the lower lobe as an option for resection. We, therefore, proceeded with pneumonectomy with an extra $10-\mathrm{mm}$ port at the $8^{\text {th }}$ intercostal space at the posterior axillary line. A standardized lymph node dissection including levels 5, 7, 9 and 10 was performed. Her pathological stage was determined to be IIIA (pT1bpN2M0), moderately differentiated adenocarcinoma. She was then enrolled in a clinical trial for chemotherapy.

\section{Discussion}

Pulmonary resection with definitive tumor staging remains the mainstay of treatment for stage I, II and se- 


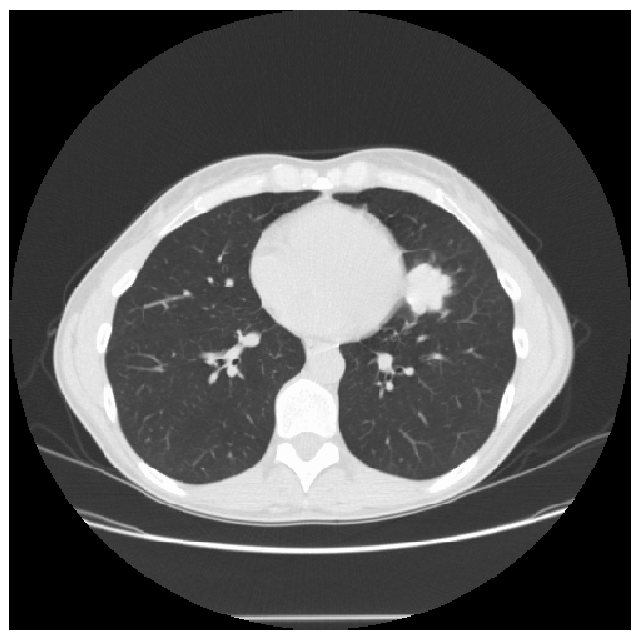

Figure 1. Lingular mass abutting the mediastinum along the left ventricle free wall.

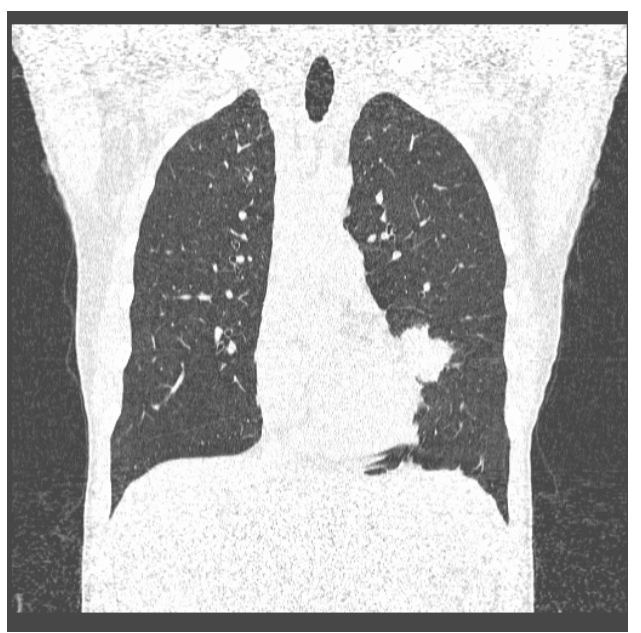

Figure 2. Coronal section of lingular mass abutting the mediastinum.

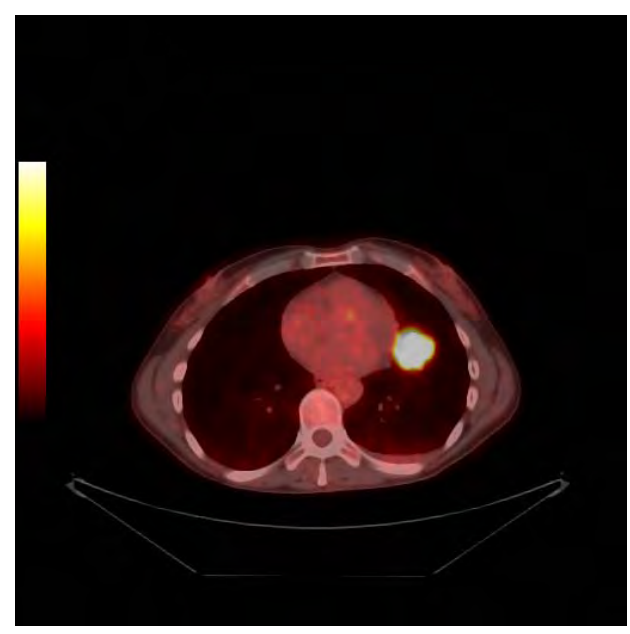

Figure 3. Positron Emission Tomography (PET) imaging revealing hypermetabolism within the lingular mass with an SUV of 10.2. lected stage III non-small cell lung cancer (NSCLC) patients. The extent of resection-lobectomy, bilobar resection, or pneumonectomy is determined principally by the location and size of the tumor [1]. Pneumonectomy is required in approximately $10 \%$ of pulmonary resections for cancer [2-10] with a mortality rate between $1.3 \%$ 11\% [11-13]. Complete resection must accomplish microscopically negative margins. CT, PET, bronchoscopy, and mediastinoscopy are the current tools employed to determine the treatment strategy however, the ultimately staging is most accurately based on surgical pathology. Lymph node status should be determined to identify the extent of disease and its stage. The likelihood of N2 node positivity discovered at surgery for clinical stage Ia tumor is less than $10 \%$; the rate rises up to $25 \%$ for clinical stage Ib [3].

Lung resection may be accomplished through open thoracotomy or VATS. Approximately $20 \%$ of all lobectomies worldwide are performed thoracoscopicall. Minimally invasive resection associated with VATS remains less commonly employed despite its advantages including decreased blood loss, shorter length of hospital stay, less pain and respiratory compromise, shorter chest tube duration, and less cost as well as shared oncologic outcomes and survival rates with open thoracoscopic lobectomies [3-6,14,15]. Oncologic validity of VATS has been established in multiple studies [7-9,16]. Yamamoto et al. reported that overall and disease-free survival rates were similar in stage matched cases for VATS and open resection [8]. Based on 4 VATS and 13 open pneumonectomy cases, they reported $85 \%$ and $83 \%$ for stage Ia and $29 \%$ and $19 \%$ for stage III disease, respectively, $\mathrm{p}>0.05$. Anatomic locations of the lesion were not reported. Sugi et al. reported similar survival rates for stage Ia cancer treated with VATS and open lobectomy (90\% and 85\% respectively, $\mathrm{p}=0.74$ ) [17]. Ohtsuka et al. recommend that a complete mediastinal lymphadenectomy (with 10 or more lymph nodes from 3 or more stations) should be done to accurately stage the mediastinum and to ensure equivalent oncologic outcomes [18]. Nwogu et al. report that nodal dissection by VATS is feasible and statistically not different than thoracotomy [19]. Sagawa et al. report that the remnant ("missed" by VATS) lymph nodes and tissues was $2 \%$ to $3 \%$, which has been deemed acceptable for clinical stage I lung cancer [20]. Cancer networks guidelines recognize VATS as a reasonable approach for treatment of lung cancer.

The largest VATS pneumonectomy case series was reported by Nwogu et al. in which 24 VATS pneumonectomies were performed and compared with 70 contemporaneous pneumonectomies by thoracotomy 15]. Both thoracoscopic and open arms had received similar neoadjuvant treatments $(4.5 \%$ and $6 \%$ for VATS and open, respectively). When compared, VATS was associated 
Table 1. Reported indications for pneumonectomy.

\begin{tabular}{|c|c|c|c|c|c|c|c|}
\hline $\begin{array}{l}\text { Pneumonectomy } \\
\text { Indication }\end{array}$ & $\begin{array}{c}\text { Bronchial } \\
\text { carcinoid [24] }\end{array}$ & $\begin{array}{l}\text { Second primary } \\
\text { cancer [25] }\end{array}$ & $\begin{array}{c}\text { Bronchiectasi } \\
\text { [26] }\end{array}$ & SCC [27] & $\begin{array}{c}\text { Malignancy NOS } \\
{[21]}\end{array}$ & $\begin{array}{c}\text { Malignancy NOS (6 } \\
\text { cases) [28] }\end{array}$ & $\begin{array}{c}\text { Adenocarcinoma } \\
\text { [29] }\end{array}$ \\
\hline Location & $\begin{array}{l}\text { Proximal R } \\
\text { bronchus }\end{array}$ & NR & NR & RUL & $\begin{array}{l}\text { LUL extending L } \\
\text { main bronchus }\end{array}$ & $\begin{array}{l}\text { Lingula, L hilum, } \\
\text { LUL, RML, and RUL }\end{array}$ & RLL \\
\hline
\end{tabular}

NR: not reported; NOS, not otherwise specified; R: right; L: left; LUL: left upper lobe; RLL: right lower lobe; RML: right middle lobe; RUL: right upper lobe.

with less intra-operative blood loss as well as a shorter hospital stay (4.5 vs 6 days). When analyzed separately, 8 conversion patients had significantly longer ICU stays in comparison to open (3.5 vs 2 days, $\mathrm{p}=0.01$ ). While a conversion to open was performed due to intra-operative bleeding and positive margins, these patients did not have higher stages or larger tumors. And while it is difficult to predict which VATS cases will require a conversion to open, a reduction in morbidity from pneumonectomy is dependent on keeping conversion rates low. Complication rates (due to arrhythmia, empyema, pneumonia, myocardial infarction, bronchopleural fistula, re-operation, or death) were similar between open and thoracoscopic cases although systematic reviews favor VATS regarding complication rates [14]. Although the VATS group included a significantly greater number of patients with early stage cancer, survival rates were similar when stratified by stage with a median follow-up of 47 months. Nwogu et al. concluded that pneumonictomy performed either by open or thoracoscopic resulted in equivalent survival.

The criteria for a VATS pneumonectomy set forth by Conlan and Sandor (2003) include centrally located lesions involving central structures, synchronous lesions, negative mediastinoscopy, small masses (up to $6 \mathrm{~cm}$ ), and a non-emphysematous lung [21]. In a recent study conducted by Riquet et al., lesions were classified into three groups according to fissure invasion: Group 1 with fissure invasion $(\mathrm{n}=154)$, Group 2 with no pleural invasion ( $\mathrm{n}=2310)$, and Group 3 with tumors extending through the elastic layer of pleura or visceral pleura $(\mathrm{n}=$ 651). The authors found that pneumonectomy was necessary in 55\% of the patients in Group 1. Despite the fact that this group had larger tumor sizes (mean $42.7 \pm 12$ $\mathrm{mm})$, intralobar invasion and pneumonectomy were found to be independent factors in poor prognosis [22]. The authors hypothesized that tumors invading through the fissure have a significant effect on long-term survival not only in the first stage of lung cancer but in all stages because of their size and important locoregional spread. We also did a literature review for pneumonectomy indications for lesions in different anatomic locations and different disease processes (Table 1). Our patient had VATS pneumonectomy because of fissure invasion in addition to the technical concerns in achieving negative margins given the close proximity to the hilar vasculature. Overall, she is doing well and has continued chemother- apy after surgery.

Despite the documented oncologic and survival success of VATS pneumonectomy, we further sought to understand why a minimally invasive VATS technique remains underutilized. Boffa et al. reported that dedicated thoracic surgeons who graduated between 2006 and 2008 considered themselves to be proficient at VATS lobectomies, where $66 \%$ of these surgeons felt that thoracic residency was critical or very important in achieving proficiency. Fellowships after completing board residency, animal labs, and follow-up VATS courses were found to be much less consistently beneficial [23]. The data may give insight into why VATS is performed in less than $40 \%$ of anatomic resections. One may conclude that VATS resection is underused given its physiologic strengths in comparison to open surgery. Therefore, we suggest that more strategies are needed to determine how a minimally invasive thoracoscopic method may become more commonly and easily applied.

In conclusion, pneumonectomy is usually preferred for central lesions not amenable to lobectomy or sleeve resection mainly due to tumor localization (i.e. close proximity to hilar structures, fissure involvement or synchronous lesions), as demonstrated in our case. Adequate oncologic outcome is not affected by VATS techniques. In fact, VATS survival rates match those of open lobectomy while adding further benefits such as decreased blood loss, decreased complication rates, shorter length of hospital stay and less cost [3-6,10]. Further controlled studies are needed to identify factors predicting the extent of surgery in the pre-operative period. Thoracic surgery fellowship training appears to be the most effective method for surgeons to become proficient in VATS and to perform this technique without hesitancy. As the thoracic surgeons feel more comfortable with VATS techniques, we can anticipate that thoracoscopic surgery will become a more conventional technique rather than a challenging procedure.

\section{REFERENCES}

[1] R. K. Sahai, C. E. Nwogu, S. Yendamuri, W. Tan, G. E. Wilding and T. L. Demmy, "Is Thoracoscopic Pneumonectomy Safe?” The Annals of Thoracic Surgery, Vol. 88, No. 4, 2009, pp. 1086-1092. doi:10.1016/j.athoracsur.2009.05.065

[2] McKenna, R. J. Jr., "Surgical Management of Primary Lung Cancer," Seminars in Oncology, Vol. 34, No. 3, 2007, pp. 250-255. doi:10.1053/j.seminoncol.2007.03.006 
[3] H. I. Libshitz, R. J. McKenna Jr. and C. F. Mountain, "Patterns of Mediastinal Metastases in Bronchogenic Carcinoma,” Chest, Vol. 90, No. 2, 1986, pp. 229-232. doi:10.1378/chest.90.2.229

[4] S. J. Swanson, B. F. Meyers, C. L. Gunnarsson, M. Moore, J. A. Howington, M. A. Maddaus, R. J. McKenna and D. L. Miller, "Video-Assisted Thoracoscopic Lobectomy Is Less Costly and Morbid than Open Lobectomy: A Retrospective Multiinstitutional Database Analysis,” The Annals of Thoracic Surgery, Vol. 93, No. 4, 2012, pp. 10271032. doi:10.1016/j.athoracsur.2011.06.007

[5] A. Mahtabifard, C. B. Fuller and R. J. McKenna Jr., "Video-Assisted Thoracic Surgery Sleeve Lobectomy: A Case Series," The Annals of Thoracic Surgery, Vol. 85, No. 2, 2008, pp. S729-S732. doi:10.1016/j.athoracsur.2007.12.001

[6] D. G. Nicastri, J. P. Wisnivesky, V. R. Litle, J. Yun, C. Chin, F. R. Dembitzer and S. J. Swanson, “Thoracoscopic Lobectomy: Report on Safety, Discharge Independence, Pain, and Chemotherapy Tolerance," The Journal of Thoracic and Cardiovascular Surgery, Vol. 135, No. 3, 2008, pp. 642-647. doi:10.1016/j.jtcvs.2007.09.014

[7] W. S. Walker, M. Codispoti, S. Y. Soon, S. Stamenkovic, F. Carnochan and G. Pugh, "Long-Term Outcomes Following VATS Lobectomy for Non-Small Cell Bronchogenic Carcinoma,” European Journal Cardio-Thoracic Surgery, Vol. 23, No. 3, 2003, pp. 397-402. doi:10.1016/s1010-7940(02)00814-X

[8] K. Yamamoto, A. Ohsumi, F. Kojima, N. Imanishi, K. Matsuoka, M. Ueda and Y. Miyamoto, "Long-Term Survival after Video-Assisted Thoracic Surgery Lobectomy for Primary Lung Cancer," The Annals of Thoracic Surgery, Vol. 89, No. 2, 2010, pp. 353-359.

doi:10.1016/j.athoracsur.2009.10.034

[9] M. W. Onaitis, R. P. Petersen, S. S. Balderson, E. Toloza, W. R. Burfeind, D. H. Harpole Jr. and T. A. D’Amico, "Thoracoscopic Lobectomy Is a Safe and Versatile Procedure: Experience with 500 Consecutive Patients,” Annals of Surgery, Vol. 244, No. 3, 2006, pp. 420-425.

[10] R. J. McKenna Jr. and W. V. Houck, "New Approaches to the Minimally Invasive Treatment of Lung Cancer," Current Opinion in Pulmonary Medicine, Vol. 11, No. 4, 2005, pp. 282-286. doi:10.1097/01.mcp.0000166589.08880.44

[11] M. S. Allen, G. E. Darling, T. T. Pechet, J. D. Mitchell, J. E. Herndon 2nd, R. J. Landreneau, R. I. Inculet, D. R. Jones, B. F. Meyers, D. H. Harpole, J. B. Putnam Jr. and V. W. Rusch, "ACOSOG Z0030 Study Group. Morbidity and Mortality of Major Pulmonary Resections in Patients with Early-Stage Lung Cancer: Initial Results of the Randomized, Prospective ACOSOG Z0030 Trial," The Annals of Thoracic Surgery, Vol. 81, No. 3, 2006, pp. 1013-1019. doi:10.1016/j.athoracsur.2005.06.066

[12] H. Wada, T. Nakamura, K. Nakamoto, M. Maeda and Y. Watanabe, "Thirty-day Operative Mortality for Thoracotomy in Lung Cancer," The Journal of Thoracic and Cardiovascular Surgery, Vol. 115, No. 1, 1998, pp. 70-73. doi:10.1016/S0022-5223(98)70444-1

[13] G. A. Silvestri, J. Handy, D. Lackland, E. Corley and C. E. Reed, "Specialists Achieve Better Outcomes than Generalists for Lung Cancer Surgery,” Chest, Vol. 114, No. 3, 1998, pp. 675-680. doi:10.1378/chest.114.3.675
[14] B. A. Whitson, S. S. Groth, S. J. Duval, S. J. Swanson and M. A. Maddaus, "Surgery for Early-Stage Non-Small Cell Lung Cancer: A Systematic Review of the VideoAssisted Thoracoscopic Surgery versus Thoracotomy Approaches to Lobectomy," The Annals of Thoracic Surgery, Vol. 86, No. 6, 2008, pp. 2008-2016. doi:10.1016/j.athoracsur.2008.07.009

[15] C. E. Nwogu, S. Yendamuri and T. L. Demmy, "Does Thoracoscopic Pneumonectomy for Lung Cancer Affect Survival?” The Annals of Thoracic Surgery, Vol. 89, No. 6, 2010, pp. S2102-S2016. doi:10.1016/j.athoracsur.2010.03.019

[16] T. D. Yan, D. Black, P. G. Bannon and B. C. McCaughan, "Systematic Review and Meta-Analysis of Randomized and Nonrandomized Trials on Safety and Efficacy of Video-Assisted Thoracic Surgery Lobectomy for EarlyStage Non-Small-Cell Lung Cancer,” Journal of Clinical Oncology, Vol. 27, No. 15, 2009, pp. 2553-2562. doi:10.1200/JCO.2008.18.2733

[17] K. Sugi, M. Sudoh, K. Hirazawa, E. Matsuda and Y. Kaneda, "Intrathoracic Bleeding during Video-Assisted Thoracoscopic Lobectomy and Segmentectomy,” Kyobu Geka, Vol. 56, No. 11, 2003, pp. 928-931.

[18] T. Ohtsuka, H. Nomori, H. Horio, T. Naruke and K. Suemasu, "Is Major Pulmonary Resection by Video-Assisted Thoracic Surgery an Adequate Procedure in Clinical Stage I Lung Cancer?” Chest, Vol. 125, No. 5, 2004, pp. 1742-1746. doi:10.1378/chest.125.5.1742

[19] C. E. Nwogu, M. Glinianski and T. L. Demmy, "Minimally Invasive Pneumonectomy," The Annals of Thoracic Surgery, Vol. 82, No. 1, 2006, pp. e3-e4. doi:10.1016/j.athoracsur.2006.04.054

[20] M. Sagawa, M. Sato, A. Sakurada, Y. Matsumura, C. Endo, M. Handa and T. Kondo, "A Prospective Trial of Systematic Nodal Dissection for Lung Cancer by VideoAssisted Thoracic Surgery: Can It Be Perfect?” The Annals of Thoracic Surgery, Vol. 73, No. 3, 2002, pp. 900904. doi:10.1016/S0003-4975(01)03409-9

[21] A. A. Conlan and A. Sandor, "Total Thoracoscopic Pneumonectomy: Indications and Technical Considerations," The Journal of Thoracic and Cardiovascular Surgery, Vol. 126, No. 6, 2003, pp. 2083-2085. doi:10.1016/S0022-5223(03)01227-3

[22] M. Riquet, P. Berna, A. Arame, P. Mordant, J. C. Das Neves Pereira, C. Foucault, A. Dujon and F. Le Pimpec Barthes, "Lung Cancer Invading the Fissure to the Adjacent Lobe: More a Question of Spreading Mode than a Staging Problem," European Journal Cardio-Thoracic Surgery, Vol. 41, No. 5, 2012, pp. 1047-1051. doi:10.1093/ejcts/ezr143

[23] D. J. Boffa, S. Gangadharan, M. Kent, F. Kerendi, M. Onaitis, E. Verrier and E. Roselli, "Self-Perceived VideoAssisted Thoracic Surgery Lobectomy Proficiency by Recent Graduates of North American Thoracic Residencies,” Interactive CardioVasc Thoracic Surgery, Vol. 14, No. 6, 2012, pp. 797-800. doi:10.1093/icvts/ivr098

[24] S. R. Craig, M. Hamzah and W. S. Walker, "Video-Assisted Thoracoscopic Pneumonectomy for Bronchial Carcinoid Tumor in a 14-Year-Old Girl," Journal of Pediatric Surgery, Vol. 31, No. 12, 1996, pp. 1724-1726. doi:10.1016/S0022-3468(96)90063-9

[25] R. Nakanishi, A. Hirai, T. Yamashita and S. Oka, "VideoAssisted Thoracoscopic Completion Pneumonectomy for 
a Second Primary Cancer: A Case Report,” The Journal of Thoracic and Cardiovascular Surgery, Vol. 135, No. 4, 2008, pp. 945-946. doi:10.1016/j.jtcvs.2007.11.043

[26] D. M. Anselmo, I. A. Perez and D. B. Shaul, "Thoracoscopic Pneumonectomy for Severe Bronchiectasis in a 9-Year-Old Female," Journal of Laparoendoscopic \& Advanced Surgical Techniques, Vol. 18, No. 5, 2008, pp. 775-777. doi:10.1089/lap.2007.0214

[27] F. J. Podbielski, G. D. Marquez, D. G. Nelson, N. A. Diettrich and M. M. Connolly, "Thoracoscopic Assisted Pneumonectomy,” JSLS, Vol. 1, No. 1, 1997, pp. 75-77.
[28] S. R. Craig and W. S. Walker, "Initial Experience of Video assisted Thoracoscopic Pneumonectomy," Thorax, Vol. 50, No. 4, 1995, pp. 392-5doi:10.1136/thx.50.4.392

[29] D Gonzalez-Rivas, M de la Torre, R Fernandez, J Garcia, "Single-Incision Video-Assisted Thoracoscopic Right Pneumonectomy,” Surgical Endoscopy, Vol. 11, 2012, pp. 26-29. 